\title{
Review Article \\ Bone Loss Triggered by the Cytokine Network in Inflammatory Autoimmune Diseases
}

\author{
Dulshara Sachini Amarasekara, Jiyeon Yu, and Jaerang Rho \\ Department of Bioscience and Biotechnology, College of Biological Sciences and Biotechnology, \\ Chungnam National University, 99 Daehak-ro, Yuseong-gu, Daejeon 305-764, Republic of Korea \\ Correspondence should be addressed to Jaerang Rho; jrrho@cnu.ac.kr
}

Received 16 October 2014; Revised 24 December 2014; Accepted 26 December 2014

Academic Editor: Giorgio Mori

Copyright (c) 2015 Dulshara Sachini Amarasekara et al. This is an open access article distributed under the Creative Commons Attribution License, which permits unrestricted use, distribution, and reproduction in any medium, provided the original work is properly cited.

\begin{abstract}
Bone remodeling is a lifelong process in vertebrates that relies on the correct balance between bone resorption by osteoclasts and bone formation by osteoblasts. Bone loss and fracture risk are implicated in inflammatory autoimmune diseases such as rheumatoid arthritis, ankylosing spondylitis, inflammatory bowel disease, and systemic lupus erythematosus. The network of inflammatory cytokines produced during chronic inflammation induces an uncoupling of bone formation and resorption, resulting in significant bone loss in patients with inflammatory autoimmune diseases. Here, we review and discuss the involvement of the inflammatory cytokine network in the pathophysiological aspects and the therapeutic advances in inflammatory autoimmune diseases.
\end{abstract}

\section{Introduction}

Bone is the main calcified tissue of vertebrates and serves multiple functions including mechanical support, protection, and storage [1]. The composition of bone is approximately $10 \%$ cells, $60 \%$ mineral crystals (crystalline hydroxyapatite), and $30 \%$ organic matrix [2]. Bone is continuously maintained by the process of bone remodeling through clusters of boneresorbing osteoclasts and bone-forming osteoblasts $[1,3]$. During bone remodeling, old or damaged bone is removed by osteoclasts and replaced by new bone formed by osteoblasts over several weeks $[1,3]$.

Osteoblasts are of mesenchymal origin and function primarily as bone-forming cells $[1,4]$. Osteoblasts secrete the organic matrix, which predominantly contains collagen, and induce calcification during the process of new bone formation [5]. During bone remodeling, osteoblasts rebuild the bone matrix in regions where the bone has been resorbed by osteoclasts $[1,4]$. The differentiation and function of osteoblasts are regulated by the activation of transcription factors (i.e., Runx-2/Cbfa-1, osterix (Osx), TAZ, and Atf4) [69], growth factors (i.e., tumor growth factor- $\beta$ (TGF- $\beta$ ), bone morphogenetic proteins (BMPs), Wnt, and vascular endothelial growth factor) [10-13], cytokines (i.e., interleukin-1 (IL-1),
IL-6, and tumor necrosis factor- $\alpha$ (TNF- $\alpha$ )), and interactions with various matrix proteins (i.e., collagen type I, biglycan, laminin, and fibronectin) [14, 15]. At the end of the boneforming phase during bone remodeling, osteoblasts incorporate into the bone as osteocytes and the rest either remain on the bone surface as lining cells or undergo apoptosis $[5,16]$.

Osteocytes are former osteoblasts that become trapped during the process of bone deposition and remain regularly distributed throughout the mineralized bone matrix. These cells comprise more than $90 \%$ of bone cells within the matrix or on bone surfaces [17]. Osteocytes are the primary mechanosensory cells that act as regulators of mineral metabolism during bone remodeling [17]. Studies have revealed that osteocytes can send signals of bone resorption to osteoclasts during bone remodeling $[17,18]$. Osteoclasts, the sole bone-resorbing cells, are multinucleated giant cells that are derived from mononuclear cells of the monocyte/macrophage lineage following stimulation by two essential factors: the macrophage colony-stimulating factor (M-CSF) and the receptor activator of nuclear factor-kappa B (RANK) ligand (RANKL) $[1,3,4]$.

The process of bone remodeling depends on the tight coupling of bone formation and bone resorption to ensure that there is no net change in the bone mass and to 


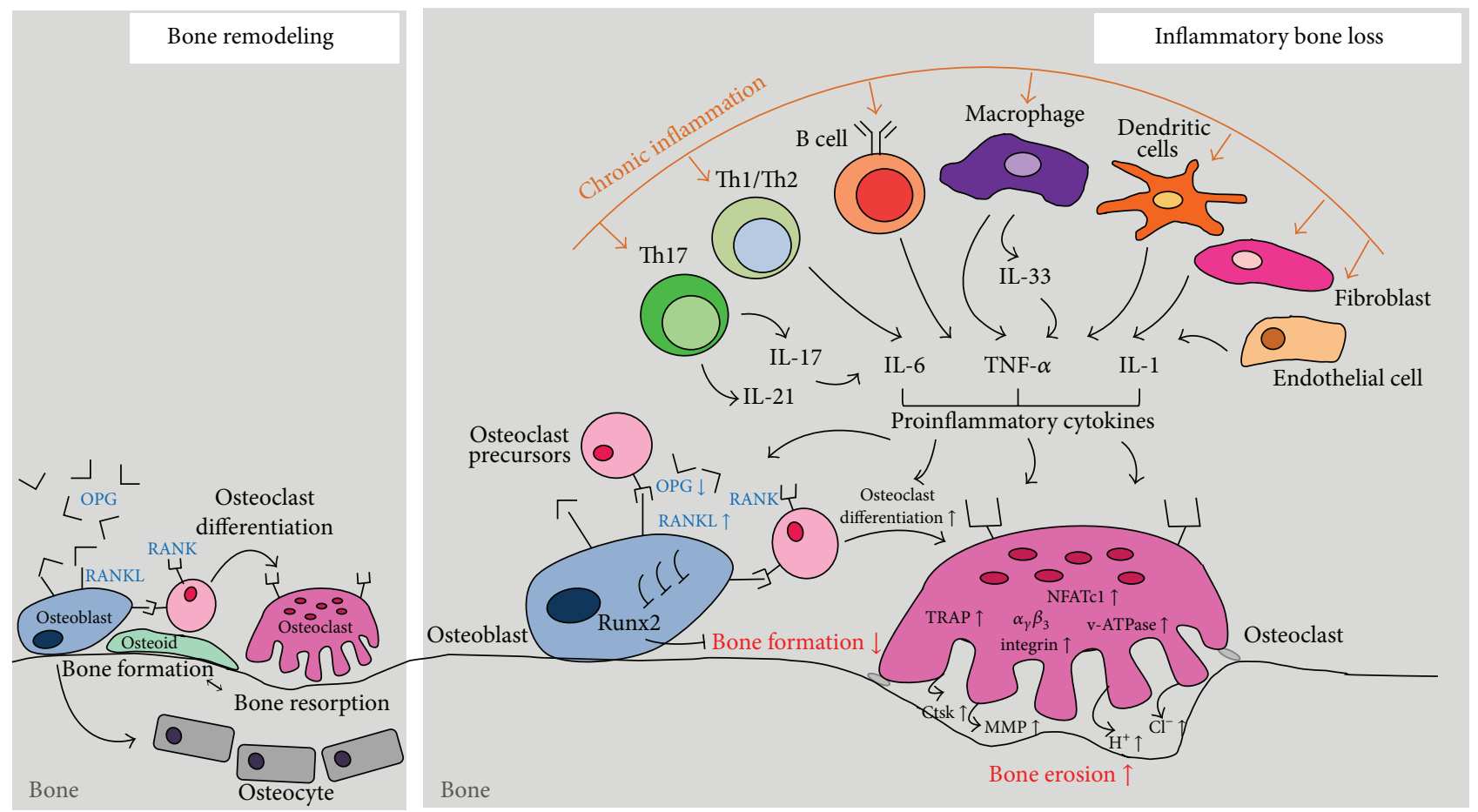

FIGURE 1: The role of inflammatory cytokine network in inflammatory bone loss. Bone remodeling is tightly regulated by the balanced action between bone-forming osteoblasts and bone-resorbing osteoclasts. In chronic inflammatory condition, inflammatory cytokine networks induce an uncoupling of bone formation and resorption that result in significant inflammatory bone loss. RANK: receptor activator of nuclear factor $\kappa$ B. RANKL: RANK ligand. OPG: osteoprotegerin. Runx2: runt-related transcription factor 2. TRAP: tartrate-resistant acid phosphatase. NFATcl: nuclear factor of activated T cells cytoplasmic 1. v-ATPase: vacuolar-type $\mathrm{H}^{+}$-ATPase. MMP: matrix metalloproteinase. Ctsk: cathepsin K.

maintain the quality after each remodeling cycle $[1,3,4]$. An imbalance in this process is closely linked to various types of bone diseases, such as osteoporosis, osteopetrosis, periodontitis, and rheumatoid arthritis (RA) [19]. Osteoporosis is a skeletal disorder characterized by compromised bone strength, predisposing patients to an increased risk of fracture [20]. Osteoporosis was first considered to be an age-related disorder characterized by low bone mass and increased bone fragility, thereby putting the patient at risk of fractures. However, over time, it has come to be viewed as a heterogeneous condition that can occur at any age and its etiology is attributed to various endocrine, metabolic, and mechanical factors [19]. Studies have reported an increased risk of developing osteoporosis in patients with various inflammatory conditions [1-4]. Inflammation is characterized by the activation of several cell populations of the innate and adaptive immune system that produce inflammatory cytokines [21]. Inflammation perturbs normal bone homeostasis and is known to induce bone loss because it promotes both local cartilage degradation and local and systemic bone destruction by osteoclasts and inhibits bone formation by osteoblasts (Figure 1).

Inflammatory joint diseases share in common the presence of an inflammatory process that targets the joints, with adverse effects on structure and function [22]. RA is one of the most common autoimmune diseases that results in chronic inflammation of the joints [23]. Autoimmune diseases are characterized by impaired function and destruction of tissues caused by the presence of autoantibodies due to abnormally activated lymphocytes and nonlymphoid cells, such as macrophages, dendritic cells, and fibroblasts [24, 25]. Dysregulation of inflammatory or anti-inflammatory cytokine production or action is reported to play a central role in the pathogenesis of autoimmune diseases such as RA, ankylosing spondylitis (AS), inflammatory bowel disease (IBD), and systemic lupus erythematosus (SLE) [26-32]. Studies have revealed that therapeutic approaches using inflammatory/anti-inflammatory cytokines, including neutralizing antibodies (i.e., anti-TNF- $\alpha$, anti-IL-6, and antiIL-17), soluble receptors/inhibitors (i.e., TNF receptor, IL1 receptor, IL-17 receptor, and IL-6 receptor inhibitor), and anti-inflammatory cytokines (i.e., IL-10 and IL-27), have been successful in controlling the progression of autoimmune diseases [33-37]. These studies have demonstrated a possible link between chronic inflammation and the pathogenesis of autoimmune diseases. Moreover, chronic inflammatory autoimmune diseases are frequently associated with bone destruction [38]. Bone loss is commonly observed in inflammatory joint diseases such as RA and AS [22]. Studies have also found an increase in bone loss and fractures with low BMD in individuals with SLE and IBD [38].

Although a large number of studies have focused on inflammatory autoimmune diseases over the past 10 years, the role of the inflammatory cytokine network involved in bone 
loss in patients with inflammatory autoimmune diseases has not been well addressed. Therefore, in this review, we will provide an overview of the interaction between inflammatory autoimmune diseases and bone destruction through the regulation of the inflammatory cytokine network.

\section{Methodology}

We performed an extensive internet search for scientific articles indexed in the PubMed/Medline database over the past 15 years using the following keywords: bone loss, osteoporosis, autoimmunity, rheumatoid arthritis, ankylosing spondylitis, inflammatory bowel disease, and systemic lupus erythematosus. We specifically focused on how bone loss and fracture risk are implicated in inflammatory autoimmune diseases.

\section{Rheumatoid Arthritis (RA)}

$\mathrm{RA}$ is a chronic autoimmune inflammatory disease characterized by the production of two main autoantibodies, rheumatoid factor and anticitrullinated peptide antibody, against common autoantigens that are widely expressed outside the joints, thereby resulting in local bone erosion, joint space narrowing, and extra-articular manifestations [23,39]. In severe cases, RA can lead to periarticular osteopenia, systemic osteoporosis, and systemic bone erosion [40]. Disturbance of bone homeostasis in RA patients is driven by the cellular action of osteoclasts [41]. The enhanced osteoclast formation and activation is due to the increased accumulation of osteoclastogenic factors in the inflamed synovium [42-45]. In RA, elevated inflammatory cytokines have been implicated in bone destruction through recruitment of osteoclast precursors to the bone environment, where they differentiate into mature osteoclasts [46-48]. These inflammatory cytokines, such as TNF- $\alpha$, IL-1, IL-6, IL-7, and IL-17, are responsible for the overexpression of RANKL and decreased levels of osteoprotegerin (OPG), a decoy receptor of RANK. This perturbation leads to an imbalance in the RANKL/OPG ratio, thereby increasing osteoclast differentiation (also known as osteoclastogenesis) [42, 49-52]. However, levels of antiinflammatory cytokines such as IL-10, IL-13, and TGF- $\beta$ have been reported to be present in significant amounts in RA joints $[53,54]$. These anti-inflammatory cytokines have a negative effect on the joint destruction and inflammation associated with RA [55].

The role of TNF- $\alpha$ in arthritic bone destruction has been demonstrated in several experimental models and confirmed by clinical trials [56]. TNF- $\alpha$ enhances osteoclastogenesis through elevated expression of RANKL in the osteoblast [57]. Moreover, TNF- $\alpha$ induces the expression of the osteoclastassociated receptor (OSCAR), a key costimulatory molecule in osteoclastogenesis, on monocytes in RA patients [58]. TNF- $\alpha$ is also involved in osteoclastogenesis through modulation of the Wnt signaling pathway, although Wnt signaling is considered to be a key regulatory pathway for bone formation by osteoblasts [59]. In RA, TNF- $\alpha$ is a strong inducer of the Wnt antagonist Dickkopf-1 (Dkk-1) expression [60]. Dkk1 impairs local bone formation through the inhibition of
Wnt signaling by binding to low density lipoprotein-coupled receptor related protein-5/6 [61]. The blockade of Dkk-1 inhibits local bone resorption by reducing osteoclast numbers through the downregulation of OPG expression in the joints; this is further compounded because OPG regulates Dkk1 expression through a feedback loop [60]. Consequently, the enhanced levels of Dkk-1 induced by TNF- $\alpha$ promote bone resorption by increasing the RANKL/OPG ratio but also block bone formation and repair in the diseased joint [62]. Furthermore, TNF- $\alpha$ is reported to directly inhibit osteoblast differentiation and bone nodule formation [63]. The transcription factors Runx-2/Cbfa- 1 and Osx, which are critical regulators of osteoblast differentiation, are reported to be inhibited by TNF- $\alpha$, thereby decreasing osteoblast differentiation and inhibiting bone formation [13]. Because TNF- $\alpha$ is the most important cytokine involved in both pathogenesis and joint inflammation associated with RA, TNF- $\alpha$ blockers were the first class of biologics used in RA [41]. A study by Smolen et al. showed that TNF- $\alpha$ blockers had a beneficial effect on inflammatory disease activity and joint degradation, achieving high rates of sustained clinical remission by preventing radiographic damage in RA [64]. Moreover, studies have reported that TNF- $\alpha$ antibodies can decrease systemic bone loss and increase bone mineral density indicating that anti-TNF- $\alpha$ can be used against systemic osteoporosis and osteopenia $[65,66]$.

IL-1 is a key regulatory cytokine in mouse models of inflammatory arthritis. Overexpression of IL- $1 \alpha$ or IL- $1 \beta$ or deletion of the IL-1 receptor antagonist (IL-1Ra) leads to the development of arthritis with cartilage and bone destruction $[48,67]$. IL-1 upregulates the production of RANKL, resulting in an imbalance in the synovial RANKL/OPG ratio [51, 68, 69]. In TNF-transgenic mice lacking IL-1 signaling, cartilage destruction is completely blocked and bone destruction partly reduced despite the presence of synovial inflammation, indicating that TNF-induced local bone destruction and systemic inflammatory bone loss are largely dependent on IL1 [48]. Moreover, it is evident that TNF-induced synthesis of RANKL is inhibited by IL-1Ra [51]. In addition to IL-1 and TNF, IL-6 is another key proinflammatory cytokine involved in the pathogenesis of RA [70]. IL-6 stimulates the synthesis of RANKL by osteoblasts and promotes the development of T helper 17 (Th17) cells together with TGF- $\beta$ and IL-1 [71]. Studies have shown that the IL- 6 antagonist tocilizumab has a beneficial effect on joint destruction and disease progression in RA patients [72, 73]. In mouse RA models, inflammatory cytokines such as IL- $1 \beta$, TNF- $\alpha$, and IL- 6 activate the signal transducer and activator of transcription 3 (STAT3) either directly or indirectly in murine osteoblasts and fibroblasts [68]. Studies have shown that STAT3 is the key mediator of both chronic inflammation and joint destruction in RA [68]. STAT3 activation induces the expression of RANKL $[68,74]$. Therefore, STAT3 inhibition is also considered to be effective in treating RA.

IL-17 is the most recently described subclass of inflammatory cytokines. IL-17 induces the secretion of proinflammatory cytokines (i.e., TNF- $\alpha$, IL- $1 \beta$, and IL-6) and chemokines (i.e., CXCL1/KC/GRO $\alpha$, CXCL2/MIP $2 \alpha / \mathrm{GRO} \beta$, CXCL8/IL-8, CCL2/MCP1, and CCL20/MIP-3 $\alpha$ ) from 
cartilage, synoviocytes, macrophages, and bone cells [75-81]. These elevated inflammatory cytokines and chemokines serve to activate and recruit neutrophils, macrophages, and lymphocytes to the inflamed synovium, thereby enhancing synovial inflammation [82]. Intra-articular injection of recombinant IL-17 also results in joint inflammation and damage $[79,83]$. Interestingly, IL-17 activity is synergistically increased when combined with proinflammatory cytokines such as TNF- $\alpha$, IL-1 $\beta$, and IL-6 [84, 85]. Moreover, IL-17 contributes to extensive cartilage and bone erosion in the advanced stages of RA by inducing the expression of RANKL, matrix metalloproteinases (MMPs), prostaglandin E2, and cyclooxygenase- $2[83,86,87]$. The role of IL-17 as a potent stimulator of osteoclastogenesis in RA patients was first demonstrated by Kotake et al. [46]. IL-17 regulates osteoclastogenesis both directly and indirectly through osteoblasts/stromal cells, although the direct effect of IL-17 on osteoclast precursors is still controversial [87-89]. IL-17 induces RANKL expression from osteoblasts, synovial cells, and mesenchymal cells, and the increased RANKL/OPG ratio results in local or systemic bone destruction through enhancement of osteoclastogenesis [42, 46, 90]. Moreover, IL-17-producing Th17 cells, a subset of RANKL-expressing $\mathrm{CD}^{+}{ }^{+} \mathrm{T}$ cells, are involved in bone destruction through the function of osteoclastogenic helper T cells [87, 91]. In animal model studies, therapeutic approaches using IL-17 antibodies or a soluble IL-17 receptor have resulted in significant suppression of joint inflammation and bone erosion through downregulation of synovial RANKL and inflammatory cytokine expression [92-94]. Therefore, blocking IL-17, the IL-17 receptor (IL-17R), or its inducers (i.e., IL-23 and IL-6) can be used as a putative treatment method for RA.

In conclusion, bone destruction in RA is caused by a complex network of inflammatory cytokines, resulting in the chronic inflammation of the synovium. These studies have revealed several promising targets for the treatment of inflammatory bone loss in RA. In this respect, the initiation of biological therapies targeting inflammatory cytokines and/or lymphocyte activation has modified RA therapy not only by blocking local and systemic inflammatory cascades but also by providing beneficial effects against bone and joint destruction.

\section{Ankylosing Spondylitis (AS)}

AS is a systemic rheumatic disease characterized by chronic inflammation that chiefly affects the sacroiliac joints and the spine, whereas RA primarily affects the synovial membrane $[95,96]$. One of the main features of structural damage in AS is bony ankyloses characterized by excessive bone formation that leads to the formation of bone spurs, such as syndesmophytes and enthesophytes, that contribute to ankylosis of the joints and poor physical function [96]. Moreover, the excessive loss of trabecular bone in the center of the vertebral body causing osteopenia or osteoporosis and leading to vertebral fractures with increased spinal deformity has been documented in AS patients [97].
TNF- $\alpha$ is a pivotal cytokine fueling inflammation in AS $[96,98]$. TNF- $\alpha$-targeted therapies have influenced shortterm control of the disease by limiting the symptoms caused by inflammation, which translates into better physical function and quality of life [96]. However, little or no effect on structural remodeling is achieved [99]. The elevated levels of IL- 1 and IL- 6 in the serum and in the sacroiliac joints of AS patients are also implicated in AS $[32,100]$. However, antibody therapies blocking IL-6R signaling with tocilizumab or sarilumab failed to show clinical efficacy in a phase II clinical trial with AS patients, suggesting that IL-6 is not a pivotal inflammatory cytokine in the pathogenesis of AS $[101,102]$.

The involvement of Th17 cells in the promotion of the inflammatory process in AS patients is shown by the significantly elevated levels of Th17 cells in the peripheral blood of patients with AS $[103,104]$. IL-17 and IL-23 are also high in the serum of AS patients [30]. Moreover, antibody therapies such as blocking IL-17 with secukinumab were shown to significantly downregulate the signs, symptoms, and objective parameters of inflammation in a phase II clinical trial in AS patients [105]. Currently, phase III clinical trials consisting of antibody therapy with secukinumab in AS patients are ongoing [106].

Previous studies have documented that the serum level of RANKL is higher in AS patients and that the expression of RANKL is increased on CD4 and CD8 T cells in AS patients [107]. Inflammatory cytokines including IL-1, IL6 , TNF- $\alpha$, and IL-17 can stimulate the expression of the soluble form of RANKL, which imbalances the RANKL/OPG ratio in AS patients [38]. The increased RANKL/OPG ratio thus promotes osteoclast differentiation, resulting in the bone destruction that is characteristic of AS $[108,109]$.

\section{Inflammatory Bowel Disease (IBD)}

IBD primarily refers to Crohn's disease and ulcerative colitis [110]. Crohn's disease can affect any part of the gastrointestinal tract, and classically presents with fatigue, prolonged diarrhea with or without gross bleeding, abdominal pain, weight loss, and fever [111]. Ulcerative colitis is limited to the colon area; common symptoms include rectal bleeding, frequent stools, mucus discharge from the rectum, tenesmus, and lower abdominal pain [111]. Crohn's disease is reported to be associated with Th1 cytokines IL-2, IL-17, interferon- $\gamma$ (IFN- $\gamma$ ), and TNF- $\alpha$, while ulcerative colitis is associated with Th2 cytokines, such as IL-4, IL-5, and IL-13 [112]. Therefore, Th1, Th2, and Th17 cells seem to be broadly involved in the pathogenesis of IBD through the regulation of inflammatory cytokine network. Interestingly, low bone matrix density (BMD) (defined as osteopenia or osteoporosis) is a known chronic complication of IBD [113]. Although IBD is not the sole risk factor for developing osteoporotic bone loss, it appears to be related to other known osteoporosis risk factors such as age, sex, body mass index, and medication [113]. Thus, the acceleration of the development of new biological drugs for IBD requires expanded insights into understanding the physiology, mechanism, and pathogenesis of IBD. 
The principal mechanisms behind reduced BMD in IBD patients are still not completely understood, but a complex network of inflammatory cytokines that influence bone destruction has been reported [110, 113]. Mucosal and systemic concentrations of many pro- and anti-inflammatory cytokines are elevated in IBD patients [114]. In particular, the enhanced production of proinflammatory cytokines such as TNF- $\alpha$, IL- $1 \beta$, and IL- 6 is well documented in IBD patients $[115,116]$. These proinflammatory cytokines stimulate bone resorption by osteoclasts through the induction of RANKL expression $[1,4]$. Interestingly, anti-TNF- $\alpha$ therapy has been shown to improve markers of bone metabolism and BMD (i.e., osteocalcin, alkaline phosphatase, and P1NP) by decreasing serum OPG levels in IBD patients [117-120]. The increased RANKL/OPG ratio is known to promote osteoclast differentiation and bone destruction in IBD patients [121].

IL-17-producing Th17 cells are considered to be a new subset of cells that is critical for the reduced BMD in chronic IBD patients [122]. Th17 cells produce IL-17, IL-17F, IL-21, and IL-22; IL-17, IL-21, and IL-22 levels were reported to be markedly elevated in IBD patients [122]. IL-21 secreted by Th17 cells is one of the crucial cytokines involved in the pathogenesis of IBD via the induction of Th1 and Th17 immune responses in the gut [110]. Studies have shown that IL-21-deficient mice were resistant to Th1/Th17 celldriven colitis $[123,124]$. Correspondingly, IL-17 and IFN- $\gamma$ production by activated lamina propria mononuclear cells from IBD patients were inhibited by an IL-21 blocking antibody $[123,124]$.

IL-33, a new member of the IL-1 family, is a ligand for the IL-1 receptor-related protein (ST2) that is anticipated to be essential for the induction of Th2 immune responses [125]. Enhanced IL-33 levels are closely associated with IBD, particularly in ulcerative colitis patients [126]. Correspondingly, the inhibition of IL-33 signaling through anti-ST2 antibody treatment attenuates the severity of arthritis in an animal RA model [127]. Furthermore, IL-33 stimulates human osteoclast differentiation through the activation of ST2 receptor signaling [128]. Thus, it may be possible that IL33 directly or indirectly regulates RANKL- or Th2 responsemediated bone loss in IBD.

Therapeutic anti-TNF- $\alpha$ antibodies such as infliximab and adalimumab are used for the treatment of severe cases of IBD $[129,130]$. However, approximately one-third of the patients benefit minimally or not at all from this treatment $[129,130]$. This could indicate that, among patients with IBD, nonresponders to anti-TNF therapy are more likely to have an inflammatory response mediated by other proinflammatory cytokines, such as IL-1 $\beta$, IL-6, IL-17, and IFN- $\gamma$. Therefore, new drugs targeting other inflammatory cytokines could potentially be useful for treating IBD patients who do not respond to anti-TNF therapy [131].

\section{Systemic Lupus Erythematosus (SLE)}

SLE is an autoimmune disease that predominantly affects young women and is characterized by immunological hyperactivity and multiorgan damage. The exact causative factors of SLE are still unknown [132]. Unrestricted hyperactivation of the immune system may lead to the overproduction of autoantibodies, immune complex deposition, and inflammatory cytokine release, eventually resulting in the SLE phenotype [132]. In particular, the dysregulation of T/B cell activation leads to the production of autoantibodies such as anti-double-stranded DNA, anti-Ro (SS-A), anti-La (SSB), anti-Smith (Sm), and anti-ribonucleoprotein (RNP) in SLE patients [133]. Autoantibodies bound with antigens are deposited in organs, thereby causing chronic inflammation and tissue damage [132].

The abnormal expression of various inflammatory cytokines due to chronic inflammation induces an imbalance among different immune cell subsets, such as Th1/Th2 and Th17/regulatory $\mathrm{T}$ (Treg) cells; this imbalance plays a crucial pathogenic role in SLE [132]. TNF- $\alpha$ has been implicated in SLE murine models [26], and elevated serum TNF- $\alpha$ levels are observed in SLE patients, similar to the other inflammatory autoimmune diseases discussed here [134]. However, the therapeutic effects of TNF- $\alpha$ blockers in SLE patients are still controversial [135]. Abnormal IL-6 levels were also observed in both serum and local tissues in patients with SLE [136]. The dominant role of IL-6 in SLE pathogenesis is to accelerate autoantibody production by promoting the proliferation of autoreactive B cells [132]. The autoantibody production induced by IL- 6 is indirectly mediated by IL- 21 produced by $\mathrm{CD}^{+}{ }^{+} \mathrm{T}$ cells [137]. Interestingly, it has been reported that IL-6 produced by dendritic cells inhibits Treg cell function in mouse SLE models [138]. Thus, IL-6 is implicated as the most important inflammatory cytokine in the pathogenesis of SLE, and antibody therapies blocking IL-6 receptor signaling with tocilizumab are reported to be effective in treating SLE [139].

IL-17 is a proinflammatory cytokine with multiple functions in the regulation of tissue inflammation [132]. An increased number of Th17 cells and elevated serum IL17 levels are reported in SLE patients [140, 141]. In SLE patients, IL-17 seems to facilitate both T cell activation and infiltration into tissues via the expression of intercellular adhesion molecule-1 (ICAM-1) and B cell activation and antibody production in combination with B-cell-activating factor (BAFF) $[140,142]$. A strong correlation between IL-17 and IL23 levels in SLE patients suggests that IL-23 contributes to SLE severity by activating Th17 cells [143]. Moreover, the IL-23/IL17 activation pathway is closely associated with increased immunoglobulin deposition and complement activation in the kidney in mouse SLE models [144]. IL-17 has not been therapeutically targeted in SLE patients to date, but data from recent clinical trials in other inflammatory autoimmune diseases such as and Crohn's disease can partially inform us about the efficacy and safety of blocking IL-17 either directly or indirectly by targeting IL-23 in SLE patients [145].

Since the first reported association between type I IFN and SLE in 1979 [146], many reports have implicated elevated levels of serum IFN- $\alpha$ in SLE [147]. Plasmacytoid dendritic cells (pDCs), which are abundant in the skin and lymph nodes, are reported to be the primary sources of IFN- $\alpha$ in SLE patients. The IFN signature produced by pDCs can 
promote the pathogenesis of SLE by enhancing autoantibody production and activating Th17 cells to secrete cytokines [148-150]. Considering the essential role of type I IFN in SLE, more than five monoclonal antibodies specific for different IFN- $\alpha$ isoforms or their receptors are in different clinical phases of testing [151].

There seems to be a high prevalence of osteoporosis in SLE patients, but the prevalence frequencies differ widely as a consequence of differences in body mass, age, sex, ethnicity, disease severity, and medication use [152]. Glucocorticoid use, longer disease duration due to chronic inflammation, neuropsychiatric disease complications, and previous fractures were identified as associated factors for SLE-related osteoporotic fractures [152]. Although the direct correlation between inflammatory cytokine levels and bone defects in SLE patients remains unclear, bone destruction in SLE patients is thought to be the result of accelerated osteoclastogenesis induced by proinflammatory cytokines [153]. The increased level of proinflammatory cytokines such as TNF- $\alpha$, IL-1, IL-6, and IL-17 in SLE patients might result in an RANKL/OPG imbalance by enhancing RANKL induction, leading to accelerated osteoclastogenesis. Interestingly, increased levels of oxidized low density lipoproteins (LDL) have been reported in SLE patients [154]. The enhanced oxidized LDL can induce T cell activation, thereby sequentially inducing RANKL expression and TNF- $\alpha$ production [154-156]. Furthermore, a recent study by Tang et al. has shown that impaired osteoblast differentiation through the inhibition of the BMP/Smad pathway by activated NF- $\kappa \mathrm{B}$ signaling plays a role in the pathology of osteoporosis in SLE patients [153]. The number of Th17 cells and IL-17 levels are elevated in the serum of many SLE patients $[140,141]$. Although the exact role of IL-17 in bone destruction in SLE patients remains unclear, IL-17 may affect bone remodeling through its effects on both osteoblasts and osteoclasts as discussed above; IL-17 can induce bone loss by mediating an imbalance in RANKL/OPG via the expression of RANKL in osteoblasts or activated $\mathrm{T}$ cells and can act in synergy with TNF- $\alpha$ or chemokines to influence osteoclast resorption $[46,75,84,85,157]$.

\section{Discussion}

Bone remodeling is a highly coordinated process that involves bone resorption and formation, which are essential for repairing damaged bones and maintaining mineral homeostasis. However, in chronic inflammatory conditions, the inflammatory cytokine network induces an uncoupling of bone formation and resorption that results in significant inflammatory bone loss. In particular, inflammatory cytokines such as IL1 , IL-6, IL-17, and TNF- $\alpha$ are involved in the pathogenesis of inflammatory autoimmune diseases of interest. However, the effects of inflammatory cytokines on inflammatory bone loss and in the pathogenesis of inflammatory autoimmune diseases are more complicated. As discussed in this review, bone loss in inflammatory autoimmune diseases may be caused by direct or indirect effects with complicated mechanisms by inflammatory cytokines or the inflammatory cytokine network in chronically inflamed tissues. Therefore, drugs targeting multiple cytokines could be an effective strategy for disease prevention and reducing disease progression. Because most inflammatory cytokines are involved in bone damage though inducing an imbalance in RANKL/OPG, focusing on OPG or RANKL management may be a better strategy than focusing on inhibiting a single cytokine.

Inflammatory autoimmune diseases continue to be a mounting public health concern worldwide. The cost and the social burden associated with these diseases, while being difficult to pin down accurately, are increasing. To stick with the saying "easing the burden: solutions for the future", it is imperative to accelerate the development of new treatment options for these diseases. A better understanding of the mechanisms by which the inflammatory cytokine network elicits chronic inflammation in autoimmunity will provide new therapeutic approaches to reduce bone destruction in inflammatory autoimmune diseases.

\section{Abbreviations}

RA: $\quad$ Rheumatoid arthritis

AS: $\quad$ Ankylosing spondylitis

IBD: Inflammatory bowel disease

SLE: $\quad$ Systemic lupus erythematosus

BMD: $\quad$ Bone mineral density

RANKL: Receptor activator of nuclear factor-kappa B ligand

M-CSF: Macrophage colony-stimulating factor

OPG: Osteoprotegerin

TNF- $\alpha$ : Tumor necrosis factor- $\alpha$

IL: Interleukin

Dkk-1: Dickkopf-1

IL-1Ra: IL-1 receptor antagonist

STAT3: Signal transducer and activator of transcription 3

MMPs: Matrix metalloproteinases

IL-17R: IL-17 receptor

IFN- $\gamma$ : Interferon- $\gamma$

Treg cells: Regulatory T cells

ICAM-1: Intercellular adhesion molecule-1

BAFF: B-cell-activating factor

pDCs: Plasmacytoid DCs

OSCAR: Osteoclast-associated receptors

Osx: Osterix

BMPs: Bone morphogenetic proteins.

\section{Disclosure}

Dulshara Sachini Amarasekara and Jiyeon Yu are co-first authors.

\section{Conflict of Interests}

The authors declare that there is no conflict of interests regarding the publication of this paper. 


\section{Acknowledgments}

This research was supported by the Basic Science Research Program through the Ministry of National Defense Foundation Grant (ADD: 14-01-06-06) and the Research Fund of Chungnam National University.

\section{References}

[1] M. C. Walsh, N. Kim, Y. Kadono et al., "Osteoimmunology: interplay between the immune system and bone metabolism," Annual Review of Immunology, vol. 24, pp. 33-63, 2006.

[2] X. Feng and J. M. McDonald, "Disorders of bone remodeling," Annual Review of Pathology: Mechanisms of Disease, vol. 6, pp. 121-145, 2011.

[3] J. Rho, M. Takami, and Y. Choi, "Osteoimmunology: interactions of the immune and skeletal systems," Molecules and Cells, vol. 17, no. 1, pp. 1-9, 2004.

[4] H. Takayanagi, "Osteoimmunology and the effects of the immune system on bone," Nature Reviews Rheumatology, vol. 5, no. 12, pp. 667-676, 2009.

[5] S.-I. Harada and G. A. Rodan, "Control of osteoblast function and regulation of bone mass," Nature, vol. 423, no. 6937, pp. 349355, 2003.

[6] P. Ducy, R. Zhang, V. Geoffroy, A. L. Ridall, and G. Karsenty, "Osf2/Cbfal: a transcriptional activator of osteoblast differentiation," Cell, vol. 89, no. 5, pp. 747-754, 1997.

[7] K. Nakashima, X. Zhou, G. Kunkel et al., "The novel zinc fingercontaining transcription factor Osterix is required for osteoblast differentiation and bone formation," Cell, vol. 108, no. 1, pp. 1729, 2002.

[8] J.-H. Hong, E. S. Hwang, M. T. McManus et al., "TAZ, a transcriptional modulator of mesenchymal stem cell differentiation," Science, vol. 309, no. 5737, pp. 1074-1078, 2005.

[9] W. Wang, N. Lian, Y. Ma et al., "Chondrocytic Atf4 regulates osteoblast differentiation and function via Ihh," Development, vol. 139, no. 3, pp. 601-611, 2012.

[10] M. Centrella, M. C. Horowitz, J. M. Wozney, and T. L. Mccarthy, "Transforming growth factor- $\beta$ gene family members and bone," Endocrine Reviews, vol. 15, no. 1, pp. 27-39, 1994.

[11] D. Chen, X. Ji, M. A. Harris et al., "Differential roles for bone morphogenetic protein (BMP) receptor type IB and IA in differentiation and specification of mesenchymal precursor cells to osteoblast and adipocyte lineages," The Journal of Cell Biology, vol. 142, no. 1, pp. 295-305, 1998.

[12] T. Gaur, C. J. Lengner, H. Hovhannisyan et al., "Canonical WNT signaling promotes osteogenesis by directly stimulating Runx2 gene expression," Journal of Biological Chemistry, vol. 280, no. 39, pp. 33132-33140, 2005.

[13] Y. Liu, A. D. Berendsen, S. Jia et al., "Intracellular VEGF regulates the balance between osteoblast and adipocyte differentiation," Journal of Clinical Investigation, vol. 122, no. 9, pp. 3101-3113, 2012.

[14] S. Mathews, R. Bhonde, P. K. Gupta, and S. Totey, "Extracellular matrix protein mediated regulation of the osteoblast differentiation of bone marrow derived human mesenchymal stem cells," Differentiation, vol. 84, no. 2, pp. 185-192, 2012.

[15] X. Wang, K. Harimoto, S. Xie, H. Cheng, J. Liu, and Z. Wang, "Matrix protein biglycan induces osteoblast differentiation through extracellular signal-regulated kinase and smad pathways," Biological and Pharmaceutical Bulletin, vol. 33, no. 11, pp. 1891-1897, 2010.
[16] R. L. Jilka, R. S. Weinstein, T. Bellido, A. M. Parfitt, and S. C. Manolagas, "Osteoblast programmed cell death (apoptosis): modulation by growth factors and cytokines," Journal of Bone and Mineral Research, vol. 13, no. 5, pp. 793-802, 1998.

[17] T. Bellido, "Osteocyte-driven bone remodeling," Calcified Tissue International, vol. 94, no. 1, pp. 25-34, 2014.

[18] A. R. Wijenayaka, M. Kogawa, H. P. Lim, L. F. Bonewald, D. M. Findlay, and G. J. Atkins, "Sclerostin stimulates osteocyte support of osteoclast activity by a RANKL-dependent pathway," PLoS ONE, vol. 6, no. 10, Article ID e25900, 2011.

[19] S. L. Teitelbaum and F. P. Ross, "Genetic regulation of osteoclast development and function," Nature Reviews Genetics, vol. 4, no. 8, pp. 638-649, 2003.

[20] N. E. Lane, "Epidemiology, etiology, and diagnosis of osteoporosis," The American Journal of Obstetrics and Gynecology, vol. 194, no. 2, pp. S3-S11, 2006.

[21] K. Redlich and J. S. Smolen, "Inflammatory bone loss: pathogenesis and therapeutic intervention," Nature Reviews Drug Discovery, vol. 11, no. 3, pp. 234-250, 2012.

[22] C. Roux, "Osteoporosis in inflammatory joint diseases," Osteoporosis International, vol. 22, no. 2, pp. 421-433, 2011.

[23] M.-C. Boissier, "Cell and cytokine imbalances in rheumatoid synovitis," Joint Bone Spine, vol. 78, no. 3, pp. 230-234, 2011.

[24] J. J. O’Shea, A. Ma, and P. Lipsky, "Cytokines and autoimmunity," Nature Reviews Immunology, vol. 2, no. 1, pp. 37-45, 2002.

[25] H.-F. Pan, X.-P. Li, S. G. Zheng, and D.-Q. Ye, "Emerging role of interleukin-22 in autoimmune diseases," Cytokine and Growth Factor Reviews, vol. 24, no. 1, pp. 51-57, 2013.

[26] M. Aringer and J. S. Smolen, "The role of tumor necrosis factoralpha in systemic lupus erythematosus," Arthritis Research and Therapy, vol. 10, article 202, 2008.

[27] T. Ciucci, L. Ibáñez, A. Boucoiran et al., "Bone marrow Th17 $\mathrm{TNF} \alpha$ cells induce osteoclast differentiation, and link bone destruction to IBD," Gut, 2014.

[28] G. Eilertsen, C. Nikolaisen, A. Becker-Merok, and J. C. Nossent, "Interleukin-6 promotes arthritis and joint deformation in patients with systemic lupus erythematosus," Lupus, vol. 20, no. 6, pp. 607-613, 2011.

[29] M. Linker-Israeli, R. J. Deans, D. J. Wallace, J. Prehn, T. OzeriChen, and J. R. Klinenberg, "Elevated levels of endogenous IL-6 in systemic lupus erythematosus: a putative role in pathogenesis," Journal of Immunology, vol. 147, no. 1, pp. 117-123, 1991.

[30] Y. Mei, F. Pan, J. Gao et al., "Increased serum IL-17 and IL-23 in the patient with ankylosing spondylitis," Clinical Rheumatology, vol. 30, no. 2, pp. 269-273, 2011.

[31] K. D. Moudgil and D. Choubey, "Cytokines in autoimmunity: role in induction, regulation, and treatment," Journal of Interferon and Cytokine Research, vol. 31, no. 10, pp. 695-703, 2011.

[32] S. K. Sharma, S. Ahmad, and S. K. Sharma, "Serum IL-6 level as a marker of disease activity in ankylosing spondylitis patients with pure axial involvement," Indian Journal of Rheumatology, vol. 9, no. 3, pp. 115-119, 2014.

[33] J. A. Fischer, A. J. Hueber, S. Wilson et al., "Combined inhibition of tumor necrosis factor $\alpha$ and interleukin-17 as a therapeutic opportunity in rheumatoid arthritis: development and characterization of a novel bispecific antibody," Arthritis \& Rheumatology, vol. 67, no. 1, pp. 51-62, 2015.

[34] C.-C. Chao, S.-J. Chen, I. E. Adamopoulos et al., "Anti-IL-17A therapy protects against bone erosion in experimental models of rheumatoid arthritis," Autoimmunity, vol. 44, no. 3, pp. 243252, 2011. 
[35] D. Hürlimann, A. Forster, G. Noll et al., "Anti-tumor necrosis factor- $\alpha$ treatment improves endothelial function in patients with rheumatoid arthritis," Circulation, vol. 106, no. 17, pp. 21842187, 2002.

[36] Y. Shirota, C. Yarboro, R. Fischer, T.-H. Pham, P. Lipsky, and G. G. Illei, "Impact of anti-interleukin-6 receptor blockade on circulating $\mathrm{T}$ and $\mathrm{B}$ cell subsets in patients with systemic lupus erythematosus," Annals of the Rheumatic Diseases, vol. 72, no. 1, pp. 118-128, 2013.

[37] J. D. Whalen, E. L. Lechman, C. A. Carlos et al., "Adenoviral transfer of the viral IL-10 gene periarticularly to mouse paws suppresses development of collagen-induced arthritis in both injected and uninjected paws," Journal of Immunology, vol. 162, no. 6, pp. 3625-3632, 1999.

[38] R. Hardy and M. S. Cooper, "Bone loss in inflammatory disorders," Journal of Endocrinology, vol. 201, no. 3, pp. 309-320, 2009.

[39] M. Vis, M. Güler-Yüksel, and W. F. Lems, "Can bone loss in rheumatoid arthritis be prevented?” Osteoporosis International, vol. 24, no. 10, pp. 2541-2553, 2013.

[40] D. Vosse and K. de Vlam, "Osteoporosis in rheumatoid arthritis and ankylosing spondylitis," Clinical and Experimental Rheumatology, vol. 27, no. 4, pp. S62-S67, 2009.

[41] T. Dimitroulas, S. N. Nikas, P. Trontzas, and G. D. Kitas, "Biologic therapies and systemic bone loss in rheumatoid arthritis," Autoimmunity Reviews, vol. 12, no. 10, pp. 958-966, 2013.

[42] E. Lubberts, L. van den Bersselaar, B. Oppers-Walgreen et al., "IL-17 promotes bone erosion in murine collagen-induced arthritis through loss of the receptor activator of NF- $\kappa \mathrm{B}$ ligand/osteoprotegerin balancel," The Journal of Immunology, vol. 170, no. 5, pp. 2655-2662, 2003.

[43] E. M. Gravallese, C. Manning, A. Tsay et al., "Synovial tissue in rheumatoid arthritis is a source of osteoclast differentiation factor," Arthritis \& Rheumatism, vol. 43, no. 2, pp. 250-258, 2000.

[44] Y. Shigeyama, T. Pap, P. Kunzler, B. R. Simmen, R. E. Gay, and S. Gay, "Expression of osteoclast differentiation factor in rheumatoid arthritis," Arthritis \& Rheumatism, vol. 43, no. 11, pp. 2523-2530, 2000.

[45] M. Stolina, S. Adamu, M. Ominsky et al., "RANKL is a marker and mediator of local and systemic bone loss in two rat models of inflammatory arthritis," Journal of Bone and Mineral Research, vol. 20, no. 10, pp. 1756-1765, 2005.

[46] S. Kotake, N. Udagawa, N. Takahashi et al., "IL-17 in synovial fluids from patients with rheumatoid arthritis is a potent stimulator of osteoclastogenesis," The Journal of Clinical Investigation, vol. 103, no. 9, pp. 1345-1352, 1999.

[47] K. Redlich, S. Hayer, A. Maier et al., "Tumor necrosis factor $\alpha$ mediated joint destruction is inhibited by targeting osteoclasts with osteoprotegerin," Arthritis and Rheumatism, vol. 46, no. 3 , pp. 785-792, 2002.

[48] J. Zwerina, K. Redlich, K. Polzer et al., “TNF-induced structural joint damage is mediated by IL-1," Proceedings of the National Academy of Sciences of the United States of America, vol. 104, no. 28, pp. 11742-11747, 2007.

[49] J. Lam, S. Takeshita, J. E. Barker, O. Kanagawa, F. P. Ross, and S. L. Teitelbaum, "TNF- $\alpha$ induces osteoclastogenesis by direct stimulation of macrophages exposed to permissive levels of RANK ligand," The Journal of Clinical Investigation, vol. 106, no. 12, pp. 1481-1488, 2000.
[50] G. Toraldo, C. Roggia, W.-P. Qian, R. Pacific, and M. N. Weitzmann, "IL-7 induces bone loss in vivo by induction of receptor activator of nuclear factor $\kappa \mathrm{B}$ ligand and tumor necrosis factor $\alpha$ from T cells," Proceedings of the National Academy of Sciences of the United States of America, vol. 100, no. 1, pp. 125-130, 2003.

[51] S. Wei, H. Kitaura, P. Zhou, F. P. Ross, and S. L. Teitelbaum, "IL-1 mediates TNF-induced osteoclastogenesis," The Journal of Clinical Investigation, vol. 115, no. 2, pp. 282-290, 2005.

[52] M. Hashizume, N. Hayakawa, and M. Mihara, "IL-6 transsignalling directly induces RANKL on fibroblast-like synovial cells and is involved in RANKL induction by TNF- $\alpha$ and IL-17," Rheumatology, vol. 47, no. 11, pp. 1635-1640, 2008.

[53] P. D. Katsikis, C.-Q. Chu, F. M. Brennan, R. N. Maini, and M. Feldmann, "Immunoregulatory role of interleukin 10 in rheumatoid arthritis," The Journal of Experimental Medicine, vol. 179, no. 5, pp. 1517-1527, 1994.

[54] P. Miossec, "Interleukin-17 in rheumatoid arthritis: if T cells were to contribute to inflammation and destruction through synergy," Arthritis \& Rheumatism, vol. 48, no. 3, pp. 594-601, 2003.

[55] J. A. G. van Roon, F. P. J. G. Lafeber, and J. W. J. Bijlsma, "Synergistic activity of interleukin-4 and interleukin-10 in suppression of inflammation and joint destruction in rheumatoid arthritis," Arthritis \& Rheumatism, vol. 44, no. 1, pp. 3-12, 2001.

[56] H. Matsuno, K. Yudoh, R. Katayama et al., "The role of TNF$\alpha$ in the pathogenesis of inflammation and joint destruction in rheumatoid arthritis (RA): a study using a human RA/SCID mouse chimera," Rheumatology, vol. 41, no. 3, pp. 329-337, 2002.

[57] Y.-H. Zhang, A. Heulsmann, M. M. Tondravi, A. Mukherjee, and Y. Abu-Amer, "Tumor necrosis factor-alpha (TNF) stimulates RANKL-induced osteoclastogenesis via coupling of TNF type 1 receptor and RANK signaling pathways," The Journal of Biological Chemistry, vol. 276, no. 1, pp. 563-568, 2001.

[58] S. Herman, G. Kroenke, R. Mueller, J. Zerina, K. Redlich, and G. Schett, "OSCAR, a key co-stimulation molecule for osteoclasts, is induced in patients with rheumatoid arthritis," Bone, vol. 43, supplement 1, p. S80, 2008.

[59] D. A. Glass II, P. Bialek, J. D. Ahn et al., "Canonical Wnt signaling in differentiated osteoblasts controls osteoclast differentiation," Developmental Cell, vol. 8, no. 5, pp. 751-764, 2005.

[60] D. Diarra, M. Stolina, K. Polzer et al., "Dickkopf-1 is a master regulator of joint remodeling," Nature Medicine, vol. 13, no. 2, pp. 156-163, 2007.

[61] B. Mao, W. Wu, Y. Li et al., "LDL-receptor-related protein 6 is a receptor for Dickkopf proteins," Nature, vol. 411, no. 6835, pp. 321-325, 2001.

[62] D. Daoussis and A. P. Andonopoulos, "The emerging role of Dickkopf-1 in bone biology: is it the main switch controlling bone and joint remodeling?" Seminars in Arthritis and Rheumatism, vol. 41, no. 2, pp. 170-177, 2011.

[63] M. Tsukasaki, A. Yamada, D. Suzuki et al., "Expression of POEM, a positive regulator of osteoblast differentiation, is suppressed by TNF- $\alpha$," Biochemical and Biophysical Research Communications, vol. 410, no. 4, pp. 766-770, 2011.

[64] J. S. Smolen, D. M. F. M. van Der Heijde, E. W. St.Clair et al., "Predictors of joint damage in patients with early rheumatoid arthritis treated with high-dose methotrexate with or without concomitant infliximab: results from the ASPIRE trial," Arthritis \& Rheumatism, vol. 54, no. 3, pp. 702-710, 2006. 
[65] N. Saidenberg-Kermanac'h, A. Corrado, D. Lemeiter, M. C. Devernejoul, M. C. Boissier, and M. E. Cohen-Solal, "TNFalpha antibodies and osteoprotegerin decrease systemic bone loss associated with inflammation through distinct mechanisms in collagen-induced arthritis," Bone, vol. 35, no. 5, pp. 1200-1207, 2004.

[66] U. Lange, J. Teichmann, U. Müller-Ladner, and J. Strunk, "Increase in bone mineral density of patients with rheumatoid arthritis treated with anti-TNF- $\alpha$ antibody: a prospective openlabel pilot study," Rheumatology, vol. 44, no. 12, pp. 1546-1548, 2005.

[67] R. Horai, S. Saijo, H. Tanioka et al., "Development of chronic inflammatory arthropathy resembling rheumatoid arthritis in interleukin 1 receptor antagonist-deficient mice," The Journal of Experimental Medicine, vol. 191, no. 2, pp. 313-320, 2000.

[68] T. Mori, T. Miyamoto, H. Yoshida et al., "IL-1 $\beta$ and TNF $\alpha$ initiated IL-6-STAT3 pathway is critical in mediating inflammatory cytokines and RANKL expression in inflammatory arthritis," International Immunology, vol. 23, no. 11, pp. 701-712, 2011.

[69] D. R. Haynes, T. N. Crotti, M. Loric, G. I. Bain, G. J. Atkins, and D. M. Findlay, "Osteoprotegerin and receptor activator of nuclear factor kappaB ligand (RANKL) regulate osteoclast formation by cells in the human rheumatoid arthritis joint," Rheumatology, vol. 40, no. 6, pp. 623-630, 2001.

[70] B. Le Goff, F. Blanchard, J.-M. Berthelot, D. Heymann, and Y. Maugars, "Role for interleukin-6 in structural joint damage and systemic bone loss in rheumatoid arthritis," Joint Bone Spine, vol. 77, no. 3, pp. 201-205, 2010.

[71] P. K. K. Wong, J. M. W. Quinn, N. A. Sims, A. Van Nieuwenhuijze, I. K. Campbell, and I. P. Wicks, "Interleukin-6 modulates production of $\mathrm{T}$ lymphocyte-derived cytokines in antigeninduced arthritis and drives inflammation-induced osteoclastogenesis," Arthritis and Rheumatism, vol. 54, no. 1, pp. 158-168, 2006.

[72] J. S. Smolen, A. Beaulieu, A. Rubbert-Roth et al., "Effect of interleukin-6 receptor inhibition with tocilizumab in patients with rheumatoid arthritis (OPTION Study): a double-blind, placebo-controlled, randomised trial," The Lancet, vol. 371, no. 9617, pp. 987-997, 2008.

[73] Y. Tanaka, T. Takeuchi, K. Amano et al., "Effect of interleukin6 receptor inhibitor, tocilizumab, in preventing joint destruction in patients with rheumatoid arthritis showing inadequate response to TNF inhibitors," Modern Rheumatology, vol. 24, no. 3, pp. 399-404, 2014.

[74] T. Miyamoto, T. Mori, A. Yoshimura, and T. Toyama, "STAT3 is critical to promote inflammatory cytokines and RANKL expression in inflammatory arthritis," Arthritis Research \& Therapy, vol. 14, supplement 1, p. P43, 2012.

[75] M. J. Ruddy, F. Shen, J. B. Smith, A. Sharma, and S. L. Gaffen, "Interleukin-17 regulates expression of the CXC chemokine LIX/CXCL5 in osteoblasts: implications for inflammation and neutrophil recruitment," Journal of Leukocyte Biology, vol. 76, no. 1, pp. 135-144, 2004.

[76] F. Fossiez, O. Djossou, P. Chomarat et al., “T cell interleukin17 induces stromal cells to produce proinflammatory and hematopoietic cytokines," The Journal of Experimental Medicine, vol. 183, no. 6, pp. 2593-2603, 1996.

[77] S. Shahrara, S. R. Pickens, A. Dorfleutner, and R. M. Pope, "IL-17 induces monocyte migration in rheumatoid arthritis," Journal of Immunology, vol. 182, no. 6, pp. 3884-3891, 2009.
[78] M. Chabaud, F. Fossiez, J.-L. Taupin, and P. Miossec, "Enhancing effect of IL-17 on IL-1-induced IL-6 and leukemia inhibitory factor production by rheumatoid arthritis synoviocytes and its regulation by Th2 cytokines," Journal of Immunology, vol. 161, no. 1, pp. 409-414, 1998.

[79] M. Chabaud, G. Page, and P. Miossec, "Enhancing effect of IL1, IL-17, and TNF-alpha on macrophage inflammatory protein3alpha production in rheumatoid arthritis: regulation by soluble receptors and Th2 cytokines," Journal of Immunology, vol. 167, no. 10, pp. 6015-6020, 2001.

[80] Y. Katz, O. Nadiv, and Y. Beer, "Interleukin-17 enhances tumor necrosis factor $\alpha$-induced synthesis of interleukins 1,6 , and 8 in skin and synovial fibroblasts: a possible role as a 'fine-tuning cytokine' in inflammation processes," Arthritis \& Rheumatism, vol. 44, no. 9, pp. 2176-2184, 2001.

[81] S.-Y. Hwang, J.-Y. Kim, K.-W. Kim et al., "IL-17 induces production of IL- 6 and IL- 8 in rheumatoid arthritis synovial fibroblasts via NF- $\kappa \mathrm{B}$ - and PI3-kinase/Akt-dependent pathways," Arthritis Research \& Therapy, vol. 6, no. 2, pp. R120-R128, 2004.

[82] F. Shen and S. L. Gaffen, "Structure-function relationships in the IL-17 receptor: implications for signal transduction and therapy," Cytokine, vol. 41, no. 2, pp. 92-104, 2008.

[83] M. Chabaud, P. Garnero, J.-M. Dayer, P.-A. Guerne, F. Fossiez, and P. Miossec, "Contribution of interleukin 17 to synovium matrix destruction in rheumatoid arthritis," Cytokine, vol. 12, no. 7, pp. 1092-1099, 2000.

[84] P. J. Koshy, N. Henderson, C. Logan, P. F. Life, T. E. Cawston, and A. D. Rowan, "Interleukin 17 induces cartilage collagen breakdown: novel synergistic effects in combination with proinflammatory cytokines," Annals of the Rheumatic Diseases, vol. 61, no. 8, pp. 704-713, 2002.

[85] A. LeGrand, B. Fermor, C. Fink et al., "Interleukin-1, tumor necrosis factor $\alpha$, and interleukin-17 synergistically up-regulate nitric oxide and prostaglandin $\mathrm{E}_{2}$ production in explants of human osteoarthritic knee menisci," Arthritis \& Rheumatism, vol. 44, no. 9, pp. 2078-2083, 2001.

[86] D. V. Jovanovic, J. Martel-Pelletier, J. A. Di Battista et al., "Stimulation of 92-kd gelatinase (matrix metalloproteinase 9) production by interleukin-17 in human monocyte/macrophages: a possible role in rheumatoid arthritis," Arthritis \& Rheumatology, vol. 43, pp. 1134-1144, 2000.

[87] K. S. A. Sato, A. Suematsu, K. Okamoto et al., "Th17 functions as an osteoclastogenic helper $\mathrm{T}$ cell subset that links $\mathrm{T}$ cell activation and bone destruction," The Journal of Experimental Medicine, vol. 203, no. 12, pp. 2673-2682, 2006.

[88] T. Yago, Y. Nanke, N. Ichikawa et al., "IL-17 induces osteoclastogenesis from human monocytes alone in the absence of osteoblasts, which is potently inhibited by anti-TNF- $\alpha$ antibody: a novel mechanism of osteoclastogenesis by IL-17," Journal of Cellular Biochemistry, vol. 108, no. 4, pp. 947-955, 2009.

[89] S. Kitami, H. Tanaka, T. Kawato et al., "IL-17A suppresses the expression of bone resorption-related proteinases and osteoclast differentiation via IL-17RA or IL-17RC receptors in RAW264.7 cells," Biochimie, vol. 92, no. 4, pp. 398-404, 2010.

[90] H. Huang, H. J. Kim, E.-J. Chang et al., "IL-17 stimulates the proliferation and differentiation of human mesenchymal stem cells: implications for bone remodeling," Cell Death and Differentiation, vol. 16, no. 10, pp. 1332-1343, 2009.

[91] J. Kikuta, Y. Wada, T. Kowada et al., "Dynamic visualization of RANKL and Th17-mediated osteoclast function," The Journal of Clinical Investigation, vol. 123, no. 2, pp. 866-873, 2013. 
[92] M. I. Koenders, E. Lubberts, B. Oppers-Walgreen et al., "Blocking of interleukin-17 during reactivation of experimental arthritis prevents joint inflammation and bone erosion by decreasing RANKL and interleukin-1," The American Journal of Pathology, vol. 167, no. 1, pp. 141-149, 2005.

[93] K. A. Bush, K. M. Farmer, J. S. Walker, and B. W. Kirkham, "Reduction of joint inflammation and bone erosion in rat adjuvant arthritis by treatment with interleukin-17 receptor IgG1 Fc fusion protein," Arthritis and Rheumatism, vol. 46, no. 3, pp. 802-805, 2002.

[94] M. Chabaud and P. Miossec, "The combination of tumor necrosis factor alpha blockade with interleukin-1 and interleukin-17 blockade is more effective for controlling synovial inflammation and bone resorption in an ex vivo model," Arthritis \& Rheumatism, vol. 44, no. 6, pp. 1293-1303, 2001.

[95] T. Pham, "Pathophysiology of ankylosing spondylitis: what's new?” Joint Bone Spine, vol. 75, no. 6, pp. 656-660, 2008.

[96] G. Schett and J.-P. David, "The multiple faces of autoimmunemediated bone loss," Nature Reviews Endocrinology, vol. 6, no. 12, pp. 698-706, 2010.

[97] N. Davey-Ranasinghe and A. Deodhar, "Osteoporosis and vertebral fractures in ankylosing spondylitis," Current Opinion in Rheumatology, vol. 25, no. 4, pp. 509-516, 2013.

[98] B. Osta, G. Benedetti, and P. Miossec, "Classical and paradoxical effects of TNF- $\alpha$ on bone homeostasis," Frontiers in Immunology, vol. 5, article 48, 2014.

[99] X. Baraliakos, H. Haibel, J. Listing, J. Sieper, and J. Braun, "Continuous long-term anti-TNF therapy does not lead to an increase in the rate of new bone formation over 8 years in patients with ankylosing spondylitis," Annals of the Rheumatic Diseases, vol. 73, no. 4, pp. 710-715, 2014.

[100] R. J. François, L. Neure, J. Sieper, and J. Braun, "Immunohistological examination of open sacroiliac biopsies of patients with ankylosing spondylitis: detection of tumour necrosis factor $\alpha$ alpha in two patients with early disease and transforming growth factor beta in three more advanced cases," Annals of the Rheumatic Diseases, vol. 65, no. 6, pp. 713-720, 2006.

[101] J. Sieper, J. Braun, J. Kay et al., "Sarilumab for the treatment of ankylosing spondylitis: results of a Phase II, randomised, double-blind, placebo-controlled study (ALIGN)," Annals of the Rheumatic Diseases, 2014.

[102] J. Sieper, B. Porter-Brown, L. Thompson, O. Harari, and M. Dougados, "Assessment of short-term symptomatic efficacy of tocilizumab in ankylosing spondylitis: results of randomised, placebo-controlled trials," Annals of the Rheumatic Diseases, vol. 73, no. 1, pp. 95-100, 2014.

[103] H. Shen, J. C. Goodall, and J. S. Hill Gaston, "Frequency and phenotype of peripheral blood Th17 cells in ankylosing spondylitis and rheumatoid arthritis," Arthritis and Rheumatism, vol. 60, no. 6, pp. 1647-1656, 2009.

[104] L. Zhang, Y. G. Li, Y. H. Li et al., "Increased frequencies of th22 cells as well as th17 cells in the peripheral blood of patients with ankylosing spondylitis and rheumatoid arthritis," PLOS ONE, vol. 7, Article ID e31000, 2012.

[105] D. Baeten, X. Baraliakos, J. Braun et al., "Anti-interleukin-17A monoclonal antibody secukinumab in treatment of ankylosing spondylitis: a randomised, double-blind, placebo-controlled trial," The Lancet, vol. 382, no. 9906, pp. 1705-1713, 2013.

[106] J. F. Zambrano-Zaragoza, J. M. Agraz-Cibrian, C. GonzálezReyes, M. D. J. Durán-Avelar, and N. Vibanco-Pérez, "Ankylosing spondylitis: from cells to genes," International Journal of Inflammation, vol. 2013, Article ID 501653, 16 pages, 2013.
[107] D. Stupphann, M. Rauner, D. Krenbek et al., "Intracellular and surface RANKL are differentially regulated in patients with ankylosing spondylitis," Rheumatology International, vol. 28, no. 10, pp. 987-993, 2008.

[108] C. H. Im, E. H. Kang, J. Y. Ki et al., "Receptor activator of nuclear factor kappa B ligand-mediated osteoclastogenesis is elevated in ankylosing spondylitis," Clinical and Experimental Rheumatology, vol. 27, no. 4, pp. 620-625, 2009.

[109] A. Leibbrandt and J. M. Penninger, "RANK/RANKL: regulators of immune responses and bone physiology," Annals of the New York Academy of Sciences, vol. 1143, pp. 123-150, 2008.

[110] A. Kaser, S. Zeissig, and R. S. Blumberg, "Inflammatory bowel disease," Annual Review of Immunology, vol. 28, pp. 573-621, 2010.

[111] K. L. Wallace, L.-B. Zheng, Y. Kanazawa, and D. Q. Shih, "Immunopathology of inflammatory bowel disease," World Journal of Gastroenterology, vol. 20, no. 1, pp. 6-21, 2014.

[112] D. Q. Shih, S. R. Targan, and D. McGovern, "Recent advances in IBD pathogenesis: genetics and immunobiology," Current Gastroenterology Reports, vol. 10, no. 6, pp. 568-575, 2008.

[113] L. E. Targownik, C. N. Bernstein, and W. D. Leslie, "Inflammatory bowel disease and the risk of osteoporosis and fracture," Maturitas, vol. 76, no. 4, pp. 315-319, 2013.

[114] G. Rogler and T. Andus, "Cytokines in inflammatory bowel disease," World Journal of Surgery, vol. 22, no. 4, pp. 382-389, 1998.

[115] M. F. Neurath and S. Finotto, "IL-6 signaling in autoimmunity, chronic inflammation and inflammation-associated cancer," Cytokine and Growth Factor Reviews, vol. 22, no. 2, pp. 83-89, 2011.

[116] H. C. Reinecker, M. Steffen, T. Witthoeft et al., "Enhanced secretion of tumour necrosis factor-alpha, IL-6, and IL-1beta by isolated lamina propria mononuclear cells from patients with ulcerative colitis and Crohn's disease," Clinical and Experimental Immunology, vol. 94, no. 1, pp. 174-181, 1993.

[117] S. G. Veerappan, C. A. O’Morain, J. S. Daly, and B. M. Ryan, "Review article: the effects of antitumour necrosis factor- $\alpha$ on bone metabolism in inflammatory bowel disease," Alimentary Pharmacology and Therapeutics, vol. 33, no. 12, pp. 1261-1272, 2011.

[118] P. Miheller, G. Muzes, K. Rácz et al., "Changes of OPG and RANKL concentrations in Crohn's disease after infliximab therapy," Inflammatory Bowel Diseases, vol. 13, no. 11, pp. 1379$1384,2007$.

[119] N. Franchimont, V. Putzeys, J. Collette et al., "Rapid improvement of bone metabolism after infliximab treatment in Crohn's disease," Alimentary Pharmacology and Therapeutics, vol. 20, no. 6, pp. 607-614, 2004.

[120] M. Pazianas, A. D. Rhim, A. M. Weinberg, C. Su, and G. R. Lichtenstein, "The effect of anti-TNF-alpha therapy on spinal bone mineral density in patients with Crohn's disease," Annals of the New York Academy of Sciences, vol. 1068, no. 1, pp. 543556, 2006.

[121] A. R. Moschen, A. Kaser, B. Enrich et al., "The RANKL/OPG system is activated in inflammatory bowel diseases and relates to the state or bone loss," Gut, vol. 54, no. 4, pp. 479-487, 2005.

[122] W. Jiang, J. Su, X. Zhang et al., "Elevated levels of Th17 cells and Th17-related cytokines are associated with disease activity in patients with inflammatory bowel disease," Inflammation Research, vol. 63, no. 11, pp. 943-950, 2014. 
[123] D. Fina, M. Sarra, M. C. Fantini et al., "Regulation of gut inflammation and Th17 cell response by interleukin-21," Gastroenterology, vol. 134, no. 4, pp. 1038.e2-1048.e2, 2008.

[124] G. Monteleone, I. Monteleone, D. Fina et al., "Interleukin21 enhances T-helper cell type I signaling and interferon- $\gamma$ production in Crohn's disease," Gastroenterology, vol. 128, no. 3, pp. 687-694, 2005.

[125] J. B. Seidelin, G. Rogler, and O. H. Nielsen, "A role for interleukin-33 in TH2-polarized intestinal inflammation," Mucosal Immunology, vol. 4, no. 5, pp. 496-502, 2011.

[126] L. R. Lopetuso, S. Chowdhry, and T. T. Pizarro, “Opposing functions of classic and novel IL-1 family members in gut health and disease," Frontiers in Immunology, vol. 4, article 181, 2013.

[127] G. Palmer, D. Talabot-Ayer, C. Lamacchia et al., "Inhibition of interleukin-33 signaling attenuates the severity of experimental arthritis," Arthritis and Rheumatism, vol. 60, no. 3, pp. 738-749, 2009.

[128] S. H. Mun, N. Y. Ko, H. S. Kim et al., "Interleukin-33 stimulates formation of functional osteoclasts from human $\mathrm{CD} 14^{+}$monocytes," Cellular and Molecular Life Sciences, vol. 67, no. 22, pp. 3883-3892, 2010.

[129] S. Mascheretti, J. Hampe, T. Kühbacher et al., "Pharmacogenetic investigation of the TNF/TNF-receptor system in patients with chronic active Crohn's disease treated with infliximab," Pharmacogenomics Journal, vol. 2, no. 2, pp. 127-136, 2002.

[130] P. Rutgeerts, W. J. Sandborn, B. G. Feagan et al., "Infliximab for induction and maintenance therapy for ulcerative colitis," The New England Journal of Medicine, vol. 353, no. 23, pp. 24622476, 2005.

[131] S. Bank, P. S. Andersen, J. Burisch et al., "Associations between functional polymorphisms in the NFkappaB signaling pathway and response to anti-TNF treatment in Danish patients with inflammatory bowel disease," The Pharmacogenomics Journal, vol. 14, pp. 526-534, 2014.

[132] D.-L. Su, Z.-M. Lu, M.-N. Shen, X. Li, and L.-Y. Sun, "Roles of pro- and anti-inflammatory cytokines in the pathogenesis of SLE," Journal of Biomedicine and Biotechnology, vol. 2012, Article ID 347141, 15 pages, 2012.

[133] O. P. Rekvig, C. Putterman, C. Casu et al., "Autoantibodies in lupus: culprits or passive bystanders?" Autoimmunity Reviews, vol. 11, no. 8, pp. 596-603, 2012.

[134] C. E. Weckerle, D. Mangale, B. S. Franek et al., "Large-scale analysis of tumor necrosis factor $\alpha$ levels in systemic lupus erythematosus," Arthritis \& Rheumatism, vol. 64, no. 9, pp. 2947-2952, 2012.

[135] M. Aringer and J. S. Smolen, "Therapeutic blockade of TNF in patients with SLE-Promising or crazy?" Autoimmunity Reviews, vol. 11, no. 5, pp. 321-325, 2012.

[136] H.-Y. Chun, J.-W. Chung, H.-A. Kim et al., "Cytokine IL-6 and IL-10 as biomarkers in systemic lupus erythematosus," Journal of Clinical Immunology, vol. 27, no. 5, pp. 461-466, 2007.

[137] O. Dienz, S. M. Eaton, J. P. Bond et al., "The induction of antibody production by IL- 6 is indirectly mediated by IL-21 produced by $\mathrm{CD}^{+} \mathrm{T}$ cells," Journal of Experimental Medicine, vol. 206, no. 1, pp. 69-78, 2009.

[138] S. Wan, C. Xia, and L. Morel, "IL-6 produced by dendritic cells from lupus-prone mice inhibits $\mathrm{CD} 4^{+} \mathrm{CD} 25^{+} \mathrm{T}$ cell regulatory functions," The Journal of Immunology, vol. 178, no. 1, pp. 271279, 2007.
[139] T. Tanaka, M. Narazaki, and T. Kishimoto, "Anti-interleukin6 receptor antibody, tocilizumab, for the treatment of autoimmune diseases," FEBS Letters, vol. 585, no. 23, pp. 3699-3709, 2011.

[140] A. Doreau, A. Belot, J. Bastid et al., "Interleukin 17 acts in synergy with B cell-activating factor to influence B cell biology and the pathophysiology of systemic lupus erythematosus," Nature Immunology, vol. 10, no. 7, pp. 778-785, 2009.

[141] H.-C. Hsu, P. Yang, J. Wang et al., "Interleukin 17-producing $\mathrm{T}$ helper cells and interleukin 17 orchestrate autoreactive germinal center development in autoimmune BXD2 mice," Nature Immunology, vol. 9, no. 2, pp. 166-175, 2008.

[142] C. Albanesi, A. Cavani, and G. Girolomoni, "IL-17 is produced by nickel-specific T lymphocytes and regulates ICAM-1 expression and chemokine production in human keratinocytes: synergistic or antagonist effects with IFN- $\gamma$ and TNF- $\alpha$," Journal of Immunology, vol. 162, no. 1, pp. 494-502, 1999.

[143] C. K. Wong, L. C. W. Lit, L. S. Tam, E. K. M. Li, P. T. Y. Wong, and C. W. K. Lam, "Hyperproduction of IL-23 and IL17 in patients with systemic lupus erythematosus: implications for Th17-mediated inflammation in auto-immunity," Clinical Immunology, vol. 127, no. 3, pp. 385-393, 2008.

[144] K. Shah, W.-W. Lee, S.-H. Lee et al., "Dysregulated balance of Th17 and Th1 cells in systemic lupus erythematosus," Arthritis Research and Therapy, vol. 12, no. 2, article R53, 2010.

[145] J. C. Martin, D. L. Baeten, and R. Josien, "Emerging role of IL-17 and Th17 cells in systemic lupus erythematosus," Clinical Immunology, vol. 154, no. 1, pp. 1-12, 2014.

[146] J. J. Hooks, H. M. Moutsopoulos, S. A. Geis, N. I. Stahl, J. L. Decker, and A. L. Notkins, "Immune interferon in the circulation of patients with autoimmune disease," New England Journal of Medicine, vol. 301, no. 1, pp. 5-8, 1979.

[147] M. K. Crow and K. A. Kirou, "Interferon-alpha in systemic lupus erythematosus," Current Opinion in Rheumatology, vol. 16, no. 5, pp. 541-547, 2004.

[148] J. Banchereau and V. Pascual, "Type I interferon in systemic lupus erythematosus and other autoimmune diseases," Immunity, vol. 25, no. 3, pp. 383-392, 2006.

[149] Z. Brkic, O. B. Corneth, C. G. van Helden-Meeuwsen et al., "T-helper 17 cell cytokines and interferon type I: partners in crime in systemic lupus erythematosus?" Arthritis Research \& Therapy, vol. 16, article R62, 2014.

[150] Z. Liu, R. Bethunaickan, W. Huang et al., "Interferon- $\alpha$ accelerates murine systemic lupus erythematosus in a T cell-dependent manner," Arthritis and Rheumatism, vol. 63, no. 1, pp. 219-229, 2011.

[151] K. A. Kirou and E. Gkrouzman, "Anti-interferon alpha treatment in SLE," Clinical Immunology, vol. 148, no. 3, pp. 303-312, 2013.

[152] I. E. M. Bultink, "Osteoporosis and fractures in systemic lupus erythematosus," Arthritis Care and Research, vol. 64, no. 1, pp. $2-8,2012$.

[153] Y. Tang, H. Xie, J. Chen et al., "Activated NF- $\kappa$ B in bone marrow mesenchymal stem cells from systemic lupus erythematosus patients inhibits osteogenic differentiation through downregulating smad signaling," Stem Cells and Development, vol. 22, no. 4, pp. 668-678, 2013.

[154] E. Svenungsson, I. Gunnarsson, G.-Z. Fei, I. E. Lundberg, L. Klareskog, and J. Frostegård, "Elevated triglycerides and low levels of high-density lipoprotein as markers of disease activity in association with up-regulation of the tumor necrosis factor 
$\alpha /$ tumor necrosis factor receptor system in systemic lupus erythematosus," Arthritis \& Rheumatism, vol. 48, no. 9, pp. 2533-2540, 2003.

[155] E. Svenungsson, G.-Z. Fei, K. Jensen-Urstad, U. de Faire, A. Hamsten, and J. Frostegård, "TNF- $\alpha$ : A link between hypertriglyceridaemia and inflammation in SLE patients with cardiovascular disease," Lupus, vol. 12, no. 6, pp. 454-461, 2003.

[156] L. S. Graham, F. Parhami, Y. Tintut, C. M. R. Kitchen, L. L. Demer, and R. B. Effros, "Oxidized lipids enhance RANKL production by $\mathrm{T}$ lymphocytes: implications for lipid-induced bone loss," Clinical Immunology, vol. 133, no. 2, pp. 265-275, 2009.

[157] F. Shen, M. J. Ruddy, P. Plamondon, and S. L. Gaffen, "Cytokines link osteoblasts and inflammation: microarray analysis of interleukin-17- and TNF- $\alpha$-induced genes in bone cells," Journal of Leukocyte Biology, vol. 77, no. 3, pp. 388-399, 2005. 


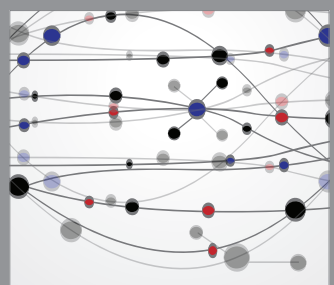

The Scientific World Journal
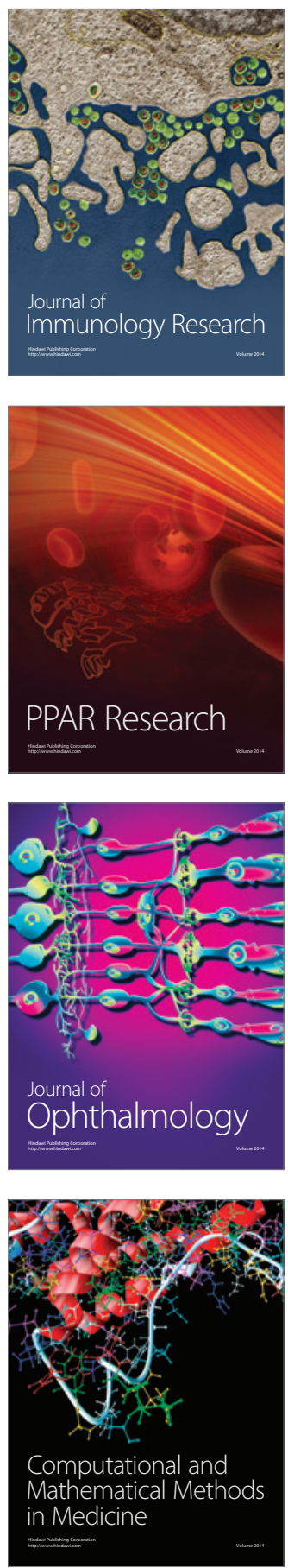

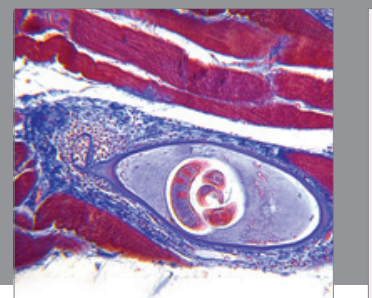

Gastroenterology

Research and Practice
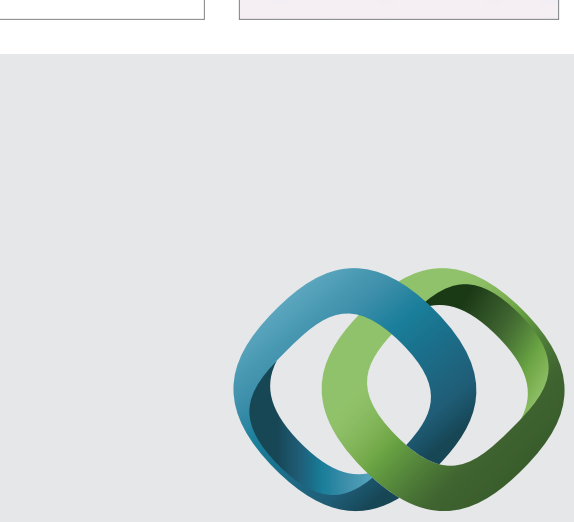

\section{Hindawi}

Submit your manuscripts at

http://www.hindawi.com
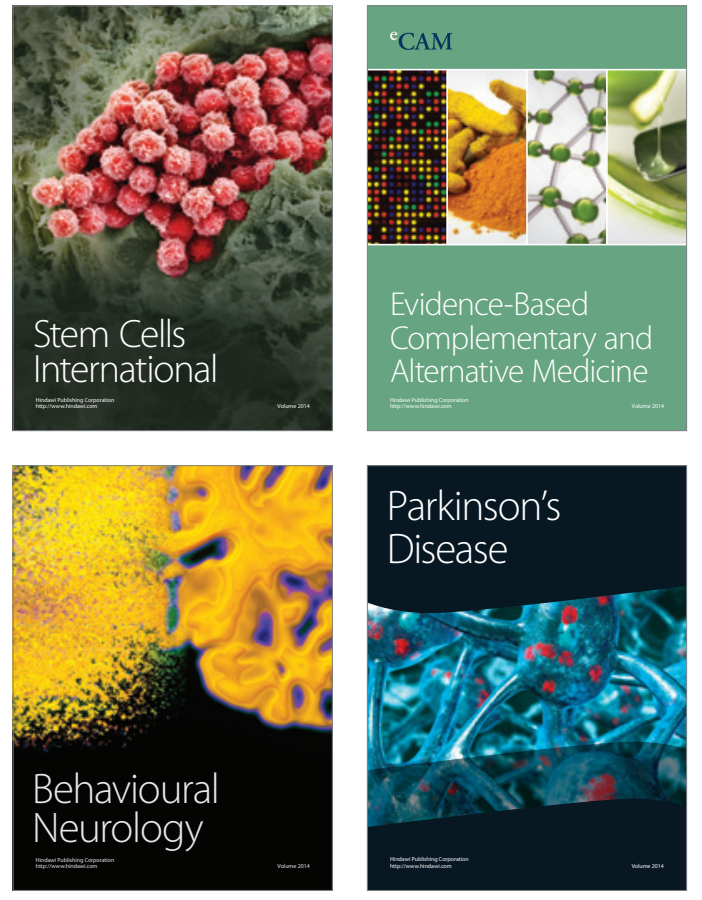
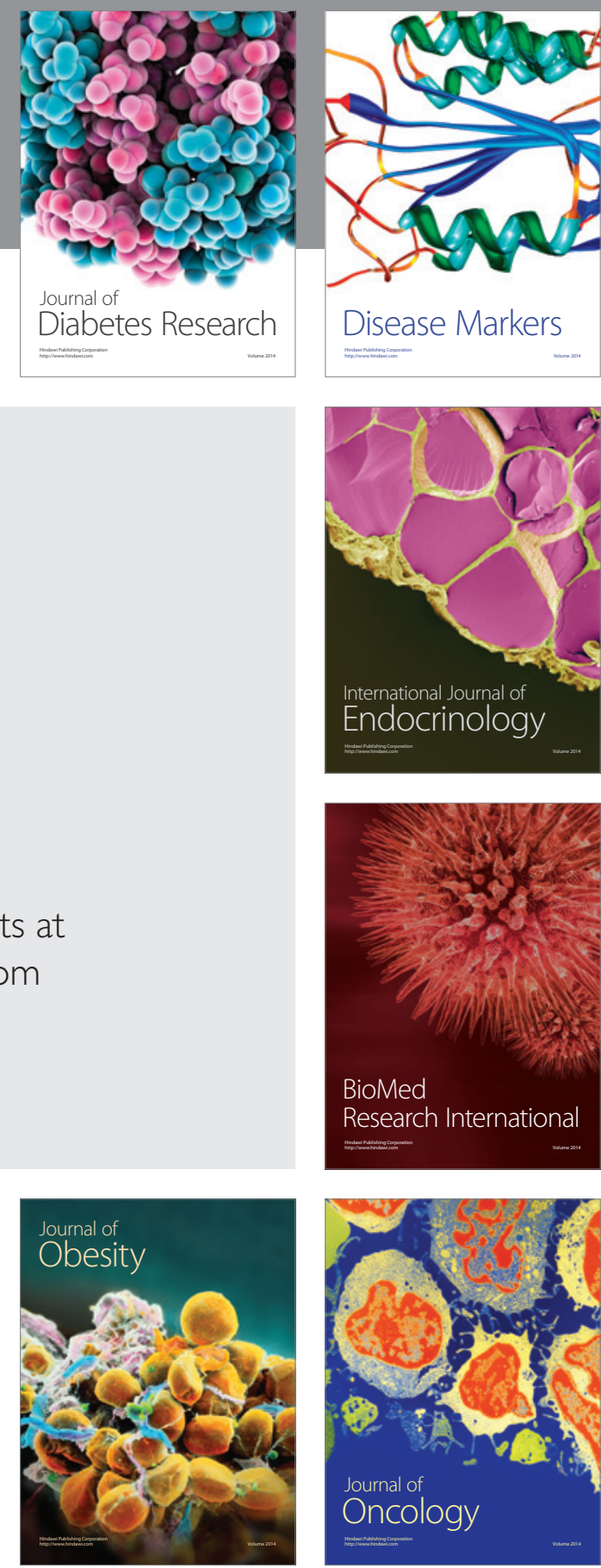

Disease Markers
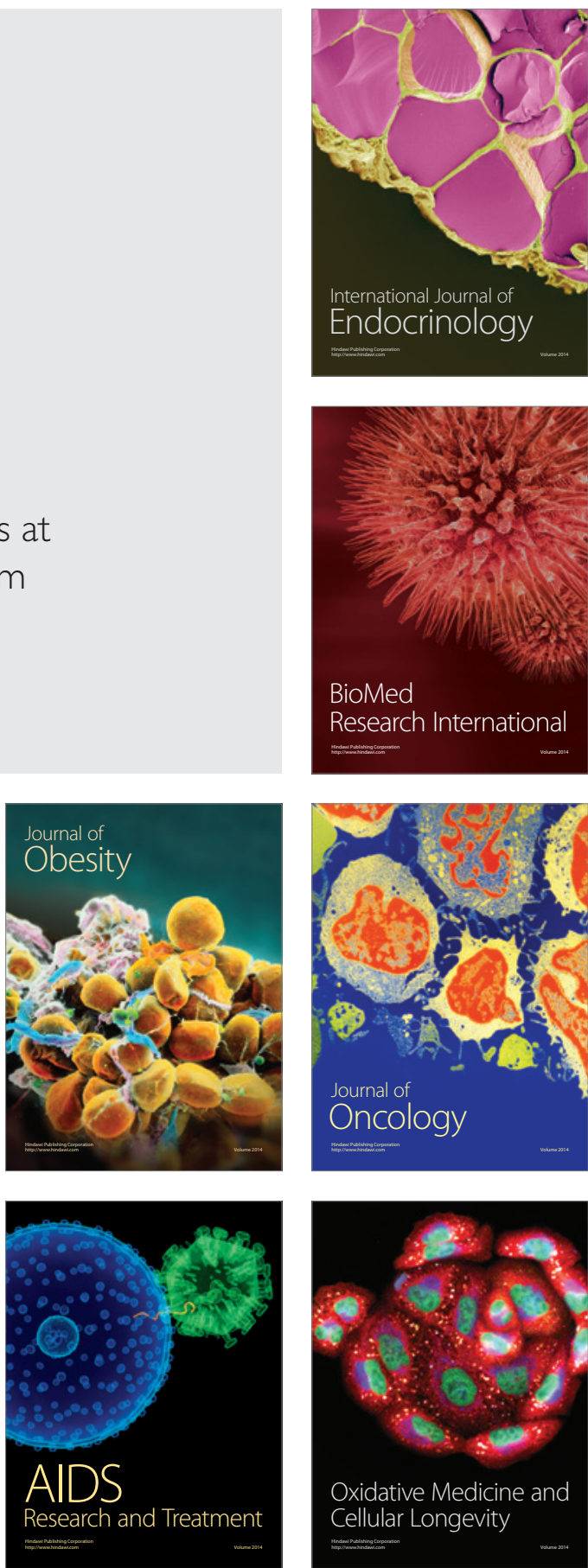